\title{
Pneumologie und Perspektiven - Was tun am Ende der Facharztausbildung
}

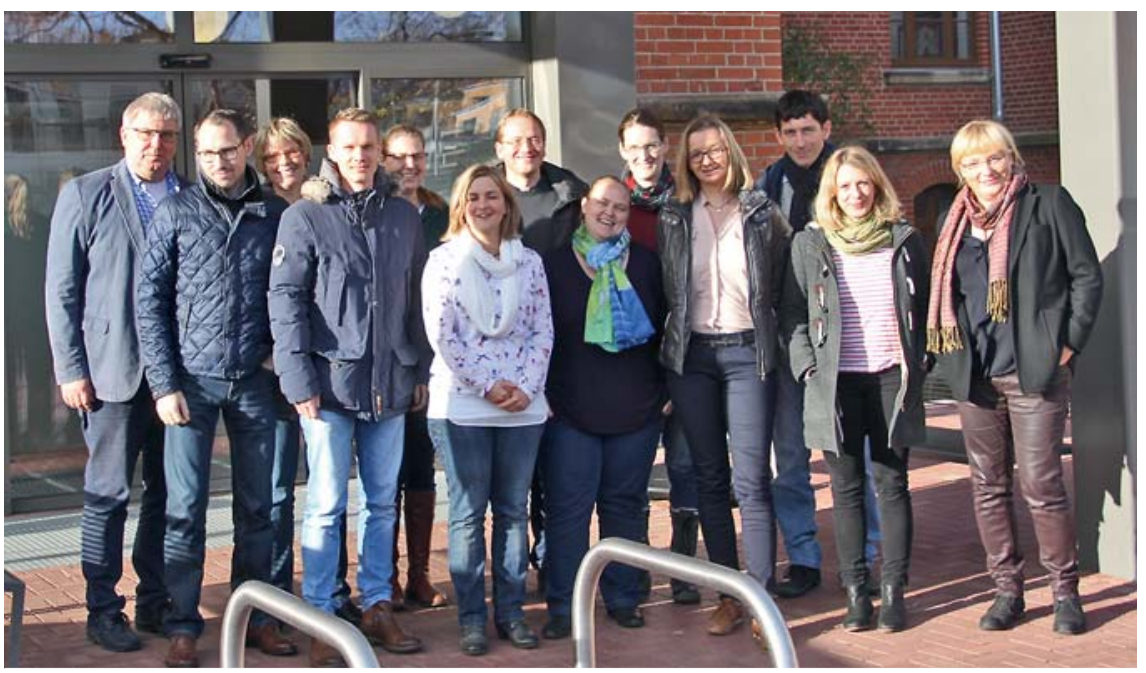

Teilnehmer der Veranstaltung Pneumologie und Perspektiven - Was tun am Ende der Facharztausbildung? Quelle: Berufsverband der Pneumologen Sachsen-Anhalt e.V.

Für junge Pneumologen in Sachsen-Anhalt gibt es vielfältige Perspektiven. Dies wurde durch den Berufsverband der Pneumologen Sachsen-Anhalt in einer Tagung am letzten Novemberwochenende eindrucksvoll dargelegt.

Dafür wandte sich der 2016 neu gewählte Vorstand des Berufsverbandes der Pneumologen Sachsen-Anhalt um Thomas Ulrich in einer ganz neuen Art und Weise den jungen Kollegen zu. Von der Universität zur Lungenklinik, über MVZ, eigene Niederlassung in einer Praxis und diverse Kooperationen untereinander und interdisziplinär wurden diese unterschiedlichen Perspektiven aufge- zeigt. Neben einem grundsätzlichen Überblick über ambulante Gestaltungsmöglichkeiten durch Dr. Burkhard John (Vorstandsvorsitzender der KV SachsenAnhalt) und Beiträgen aus Sicht einer Kardiologin sowie eines Onkologen wurden auch finanzielle Aspekte der pneumologischen Tätigkeit in Anstellung und Niederlassung dargelegt. Prof. Jens Schreiber, Direktor der Universitätslungenklinik Magdeburg, wagte einen Blick in die Zukunft und thematisierte die Pneumologie in 10 oder 20 Jahren, Frau Dr. med. Barbara Wagener, Präsidentin der MDGP und Chefärztin der Lungenklinik Ballenstedt referierte über Perspektiven des weiblichen Nachwuchses.

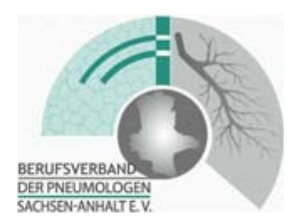

Insgesamt wurde im Gesundheitszentrum „Alte Schule“ in Halberstadt sehr konkret und persönlich berichtet und diskutiert. Auch das abendliche Rahmenprogramm, eine Führung durch den Halberstädter Dom mit Besichtigung des Domschatzes, trug zu dieser sehr nahbaren Atmosphäre bei und ließ viel Raum für offene Gespräche.

Klar geworden ist an diesem Wochenende, dass die Pneumologie nach wie vor ein spannendes und zukunftsträchtiges Fachgebiet ist und mehr denn je die Vernetzung und Kooperation untereinander und mit anderen Fachgebieten benötigt.

Es bleibt zu wünschen, dass dieses innovative, hilfreiche Tagungsformat, welches unter der Schirmherrschaft der Mitteldeutschen Gesellschaft für Pneumologie (MDGP) und des Berufsverbandes der Pneumologen Sachsen-Anhalt durchgeführt wurde, eine baldige Fortsetzung findet und der Berufsverband weiter ein Interesse hat, die Kommunikation mit dem pneumologischen Nachwuchs in Sachsen-Anhalt zu fördern.

Uta Ziehn, Berufsverband der Pneumologen (BdP) 